\title{
Influence of Dietary Fish Oil on the Aortic, Myocardial, and Renal Lesions of SHR
}

\author{
Tetsuo Shimamura and Alan C. Wilson \\ University of Medicine and Dentistry of New Jersey, Robert Wood Johnson \\ Medical School, 675 Hoes Lane, Piscataway, N. J. 08854, U.S.A.
}

(Received June 18, 1991)

\begin{abstract}
Summary To examine the effects of menhaden oil on the progressive glomerulosclerosis, arteriosclerosis, plasma cholesterol and triglyceride levels, and myocardial damage, spontaneously hypertensive rats (SHR) were fed Purina rat chow supplemented either with $6 \mathrm{~g} \%$ of menhaden oil or with $6 \mathrm{~g} \%$ of corn oil. They were sacrificed on the 12th and 18th months, and the kidneys, aorta, and heart were examined by light microscopy. At sacrifice, body weight, plasma creatinine, systolic blood pressure, $24 \mathrm{~h}$ ' urinary protein output, total plasma cholesterol and triglyceride, glomerular filtration rate (GFR), and glomerulosclerosis index were measured. There was no significant difference between the experimental and control groups in the average body weight, plasma creatinine level, systolic blood pressure, total $24 \mathrm{~h}$ urinary protein output, and glomerular filtration rate. Rats with menhaden oil had, however, statistically significant less aortic arteriosclerosis, myocardial damage, plasma cholesterol and triglyceride levels, and renal interstitial fibrosis than those with corn oil. The glomerular damage of the former as expressed by glomerulosclerosis index was numerically less than that of the latter. The data indicated that menhaden oil lessened the hypertensive damage to the renal and cardiovascular systems.
\end{abstract}

Key Words spontaneously hypertensive rat, glomerulosclerosis, renal interstitial fibrosis, arteriosclerosis, myocardial lesions, fish oil, $\omega-3$ fatty acid, hypertension

Renal tissue damage takes place in spontaneously hypertensive rats (SHR). Sustained hypertension in man similarly injures renal tissue. Fish oil containing $\omega-3$ fatty acids has been reported to reduce the incidence of cardiovascular disease (1-5). However, little is known whether fish oil similarly lessens the hypertensive kidney damage. Furthermore, a controversy persists over its preventive effects on arteriosclerosis or hypertensive cardiovascular diseases (6-11). SHR are an excellent model to examine the effects of fish oil on the development of hypertensive 
renal damage, arteriosclerosis, and myocardial infarct. This study is, therefore, mainly to examine whether menhaden oil administered to SHR will alleviate arteriosclerosis of the aorta, renal lesions, and cardiac damage.

\section{MATERIALS AND METHODS}

Forty SHR, 5-week-old males, were used. Twenty and 20 rats were fed with Purina rat chow supplemented with $6 \mathrm{~g} \%$ menhaden oil (Zepata Haynie, Va.) and $6 \mathrm{~g} \%$ corn oil (ICN Nutr. Biochem., Cleveland), respectively. Fatty acid composition and vitamin $\mathrm{E}$ content of these oils are shown in Table 1. The food was freshly prepared once weekly and kept at minus $20^{\circ} \mathrm{C}$. Each day, the residual food was discarded and fresh food provided. Two experimental and 4 control rats expired before the end of the experiment, and these were excluded from the study. At the end of the 12th month, 7 experimental and 7 control rats were sacrificed, and the remainder sacrificed at the end of the 18th month. At the time of sacrifice, plasma creatinine level was determined by alkaline picrate method, and the total 24 $\mathrm{h}$ urinary protein output was calculated following measurement of a urinary protein concentration by microLowry method (12) in the urine samples collected for $24 \mathrm{~h}$. In only those rats that were sacrificed at the end of 18th month, the glomerular filtration rate was determined by the method reported by Morrison and Howard (13). The total plasma cholesterol and triglyceride levels were measured by enzymatic method by using the assay kits (Sigma Chem. Co., St. Louis, Mo.) (14). At the beginning and at the times of sacrifice, the systolic blood pressure was measured by the tail-cuff method using physiograph desk model DMP-4B (Narco Biosystems, Inc., Houston, Tex.) and programmed electro-sphygmomanometer PE-300 (Narco Biosystems, Inc., Houston, Tex.) under mild ether anesthesia. The

Table 1. Fatty acid composition of menhaden and corn oils.

\begin{tabular}{|c|c|c|c|c|c|}
\hline \multicolumn{2}{|c|}{ Menhaden oil (\%) } & \multirow[b]{2}{*}{$\mathrm{C} 20$} & \multirow[b]{2}{*}{0.20} & \multicolumn{2}{|c|}{ Corn oil (\%) } \\
\hline C14 & 8.02 & & & $\mathrm{C} 12: 0$ & Trace \\
\hline $\mathrm{C} 15$ & 0.69 & $\mathrm{C} 20: 1$ & 1.53 & $\mathrm{C} 14: 0$ & Trace \\
\hline $\mathrm{C} 16$ & 15.96 & $\mathrm{C} 20: 2$ & 0.13 & $\mathrm{C} 16: 0$ & 11.2 \\
\hline $\mathrm{C} 16: 1$ & 10.16 & $\mathrm{C} 20: 3$ & 0.42 & $\mathrm{C} 18: 0$ & 2.1 \\
\hline $\mathrm{C} 16: 2$ & 1.58 & $\mathrm{C} 20: 4$ & 2.06 & $\mathrm{C} 18: 1$ & 25.0 \\
\hline $\mathrm{C} 16: 3$ & 1.91 & $\mathrm{C} 20: 5$ & 13.39 & $\mathrm{C} 18: 2$ & 59.9 \\
\hline $\mathrm{C} 16: 4$ & 1.03 & $\mathrm{C} 21: 5$ & 0.66 & $\mathrm{C} 18: 3$ & 0.5 \\
\hline $\mathrm{C} 17$ & 0.63 & $\mathrm{C} 22$ & 0.12 & & \\
\hline $\mathrm{C} 18$ & 2.69 & $\mathrm{C} 22: 1$ & 0.22 & & \\
\hline $\mathrm{C} 18: 1$ & 9.50 & $\mathrm{C} 22: 4$ & 0.16 & & \\
\hline $\mathrm{C} 18: 2$ & 1.04 & $\mathrm{C} 22: 5$ & 2.59 & & \\
\hline $\mathrm{C} 18: 3$ & 1.21 & $\mathrm{C} 22: 6$ & 8.44 & & \\
\hline C18:4 & 3.06 & $\mathrm{C} 24: 1$ & 0.24 & & \\
\hline
\end{tabular}


kidneys, aorta, and heart were fixed in buffered $10 \%$ formalin, embedded in paraffin, sectioned, and stained with hematoxylin and eosin, and periodic acid-Schiff's reagent (PAS). The glomerulosclerosis was light microscopically graded in 100 glomeruli of each rat and expressed as sclerosis index as previously reported (15). The aorta and heart were histologically evaluated only in those rats that were sacrificed at the end of the 18th month. Degrees of the intimal thickness were determined in the longitudinal section of the thoracic and abdominal segments of the aorta by a reticle mounted on a microscope eyepiece lens. The presence of thickened intimal area, $20 \mu \mathrm{m}$ or more in thickness, was classified as positive arteriosclerosis, and the intimal thickness of less than $20 \mu \mathrm{m}$ regarded as absent of arteriosclerosis. In addition, the total length of each arteriosclerotic intimal area as defined above was measured by morphometry using Zeiss MOP-III coupled with Nikon Labphoto with a drawing tube. The total length of arteriosclerotic area was then divided by the total intimal length of the aortic section, and the value obtained was expressed as percent area of involvement. A coronal section of each heart was made including both atria, both ventricles, and the septum at the site of the maximum cardiac diameter. A presence or absence of a myocardial infarct or fibrosis exceeding $1 \mathrm{~mm}$ in maximum dimension was light microscopically examined using microscope eyepiece reticle. All average numerical values were expressed with standard error of means and were analyzed by Student's $t$-test unless otherwise specified.

\section{RESULTS}

\section{Body weight}

The average body weights of the experimental and control rats sacrificed on the 12 th month were $424 \pm 5$ and $429 \pm 5 \mathrm{~g}$, respectively, $(p=0.56)$. On the 18 th month, the average body weights of the experimental and control rats were 397士 12 and $412 \pm 3 \mathrm{~g}$, respectively, $(p=0.32)$. There was no significant difference between the 2 groups on the 12 th and 18 th months.

\section{Kidneys}

The average kidney weights of the experimental and control rats were $3.32 \pm$ 0.06 and $3.36 \pm 0.08 \mathrm{~g}$ on the 12 th month $(p=0.71)$; and were $3.42 \pm 0.13$ and $3.42 \pm 0.06 \mathrm{~g}$ on the $18 \mathrm{th}$ month, respectively, $(p=0.99)$. There was no significant difference between the 2 groups on the 12th and 18th months. The glomerular lesions occurred predominantly in the juxtamedullary or deep cortical areas. The glomerulosclerosis was segmental (Fig. 1) to global (16). The altered glomeruli demonstrated mesangial expansion, obliteration of the capillary lumina, and focal segmental necrosis of the glomerular tufts. The expanded mesangial matrix stained intensely with PAS. The capillary lumina of severely sclerosed glomeruli were often obliterated by PAS-positive proteinaceous material. The global glomerulosclerosis was almost exclusively present only in the juxtamedullary glomeruli, but not in the 


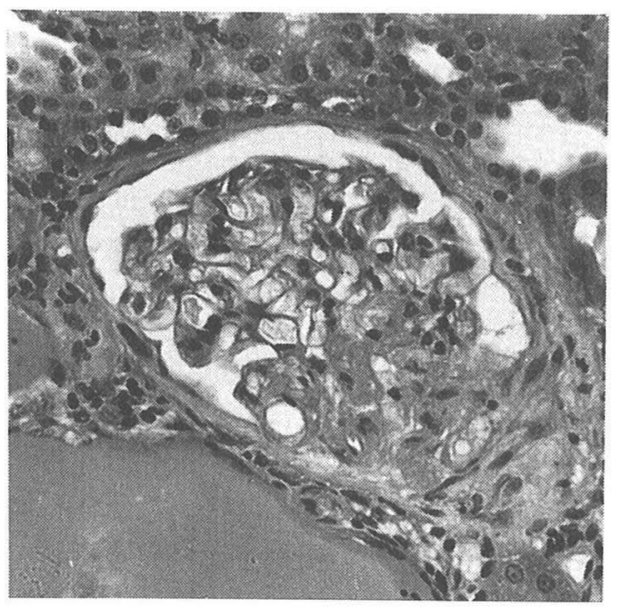

Fig. 1. Segmental glomerulosclerosis of a rat that was fed the corn-oil-supplemented diet for 18 months. H \& E, $\times 234$.

superficial cortical glomeruli, as late as the 18th month both in the experimental and control rats. The glomerulosclerosis indices of the experimental and control rats were $0.357 \pm 0.055$ and $0.434 \pm 0.062$ on the 12 th month $(p=0.37)$; and were $0.799 \pm 0.09$ and $0.963 \pm 0.041$ on the 18 th month, respectively, $(p=0.25)$. The glomeruli of the experimental and control rats sacrificed on the 18th month showed more severe changes than those sacrificed on the 12th month. The glomerulosclerosis index of the experimental rats on the 18th month was significantly higher than that of the experimental rats at 12th month $(p<0.002)$. Similarly, the glomerulosclerosis index of the control rats at 18 th month was significantly higher than that of the controls at 12 th month $(p<0.002)$. The cortical tissue demonstrated scattered microscopic foci of mild interstitial fibrosis both in the experimental and control rats on the 12th month, but there was little difference in degrees of the fibrotic process on the 12 th month. Foci of microscopic interstitial fibrosis were, however, more prominent on the 18th month. Twenty-five randomly selected fields of multiple renal cortical sections examined under $10 \times$ objective lens demonstrated an average presence of microscopic focal fibrosis in $12.1 \pm 1.0$ fields out of 25 in the experimental rats, and in $15.0 \pm 0.4$ fields out of 25 in the control rats, and the difference between the experimental and control groups was statistically significant $(p<0.03)$. The fibrosed areas were often associated with a small number of atrophic tubules with thickened basement membrane.

\section{Blood pressure}

The average levels of the systolic blood pressure of the experimental and control rats were $104 \pm 2$ and $104 \pm 3 \mathrm{mmHg}$ at the beginning of the experiment; $172 \pm 10$ and $170 \pm 6 \mathrm{mmHg}$ at the 12 th month $(p=0.88)$; and 174 \pm 10 and 182 $10 \mathrm{mmHg}$ at the 18 th month $(p=0.58)$, respectively. Both groups were hyper- 
tensive on the 12th and 18th months, but there was no significant difference in the levels of the systolic blood pressure between the 2 groups on the 12th and 18th months.

\section{Urinary protein output}

The average values of $24 \mathrm{~h}$ total urinary protein output of the experimental and control rats were $190 \pm 31$ and $197 \pm 23 \mathrm{mg}$ at the 12 th month $(p=0.85)$; and were $285 \pm 43$ and $254 \pm 29 \mathrm{mg}$ at the $18 \mathrm{th}$ month $(p=0.59)$, respectively. There was no significant difference between the 2 groups on the 12 th and 18 th months.

\section{Plasma creatinine level}

The average plasma creatinine levels of the experimental and controls were $0.53 \pm 0.02$ and $0.51 \pm 0.02 \mathrm{mg} / \mathrm{dl}$ at the 12 th month; and $0.62 \pm 0.03$ and $0.55 \pm 0.05$ $\mathrm{mg} / \mathrm{dl}$ at the $18 \mathrm{th}$ month, respectively. None of the rats were in renal failure.

\section{Total plasma cholesterol and triglyceride levels}

The average total plasma cholesterol levels of the experimental and control rats on the 18 th month were $94 \pm 6$ and $124 \pm 7 \mathrm{mg} / \mathrm{dl}$, respectively. The rats with dietary supplementation of menhaden oil exhibited a significantly lower plasma cholesterol level $(p<0.03)$. The average plasma triglyceride levels of the experimental and controls on the 18 th month were $97 \pm 11$ and $141 \pm 20 \mathrm{mg} / \mathrm{dl}$, respectively. The SHR with menhaden oil demonstrated a significantly lower plasma triglyceride level than that of the controls $(p<0.05)$.

\section{Glomerular filtration rate (GFR)}

The average glomerular filtration rates of the experimental and control groups at 18 th month were $0.539 \pm 0.042$ and $0.521 \pm 0.032 \mathrm{ml} / \mathrm{min} / \mathrm{g}$ kidney weight, respectively. There was no significant difference between the 2 groups $(p=0.70)$, and the GFR values showed little evidence of ranal functional impairment as late as the 18 th month in both groups.

\section{Aortic intimal lesions}

Aortae of both groups of rats exhibited focal subendothelial acellular or cellular thickening (Fig. 2). All these lesions were grossly nondetectable microscopic lesions, and were only observable by meticulous search (17). The intimal thickening measuring $20 \mu \mathrm{m}$ or more were present in 2 of the experimental and 6 of the control rats $(p<0.04$, one-tailed Fisher's exact test). The intimal thickening was much more pronounced and more widely spread in rats without fish oil (Fig. 3 ). These proliferative intimal cells were elongated in shape echibiting characteristics of myointimal cells. Some of the proliferating intimal cells were hypertrophic with mildly hyperchromatic enlarged nuclei (Fig. 4). The percent areas of the arteriosclerosis of the experimental and control rats were $0.03 \pm 0.02$ and $0.39 \pm$ 0.17 , respectively. The SHR with menhaden oil demonstrated significantly less 


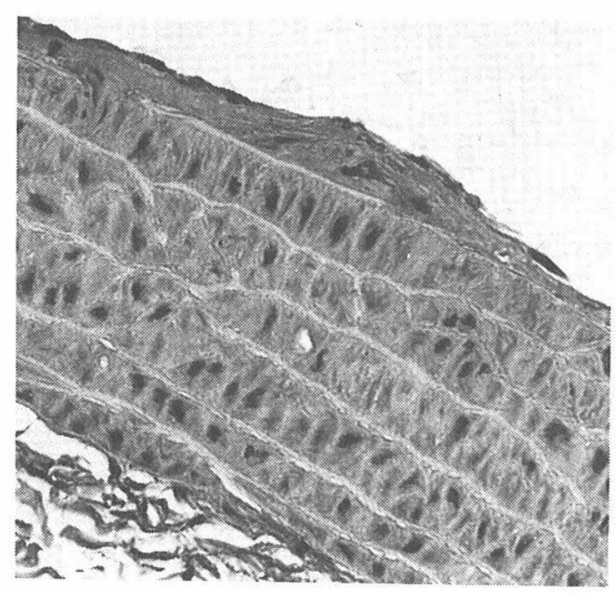

Fig. 2. A minor intimal thickening of a rat with fish-oil-supplemented diet for 18 months. Inside of the internal elastic lamina are several cells and increase in extracellular matrix. H \& E, $\times 279$.

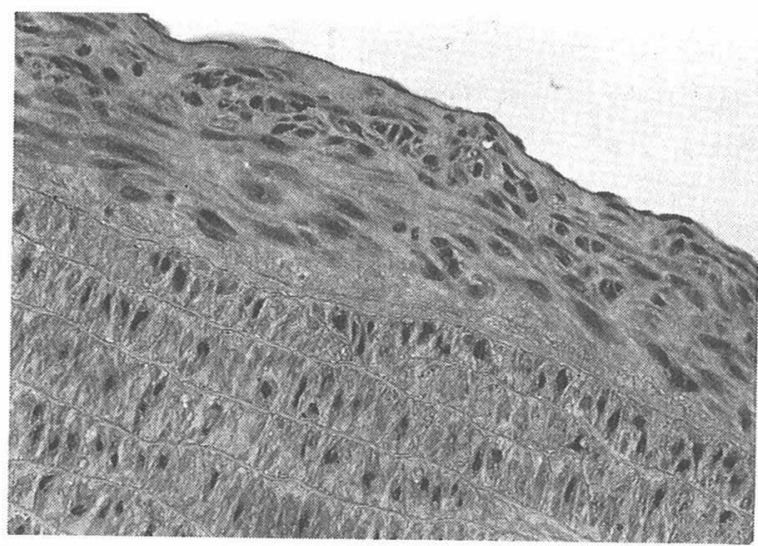

Fig. 3. A rather prominent fibrocellular intimal thickening of a rat with corn-oilsupplemented diet for 18 months. Some intimal cells are enlarged in size with a large nucleus. The media exhibits orderly stepladder-like arrangement of smooth muscle cells between elastic fibers. H \& E, $\times 215$.

involvement of the aortic intimal surface area than that of the controls $(p<0.04)$.

\section{Myocardium}

None of the rats with fish oil demonstrated a myocardial fibrous replacement exceeding $1 \mathrm{~mm}$ in the maximum dimension. On the contrary, 5 of the rats without fish oil exhibited myocardial infarct or fibrous replacement exceeding $1 \mathrm{~mm}$ in maximum dimension (Fig. 4). The difference in the incidence was statistically significant $(p<0.01$, one-tailed Fisher's exact test). The cardiac indices of the 


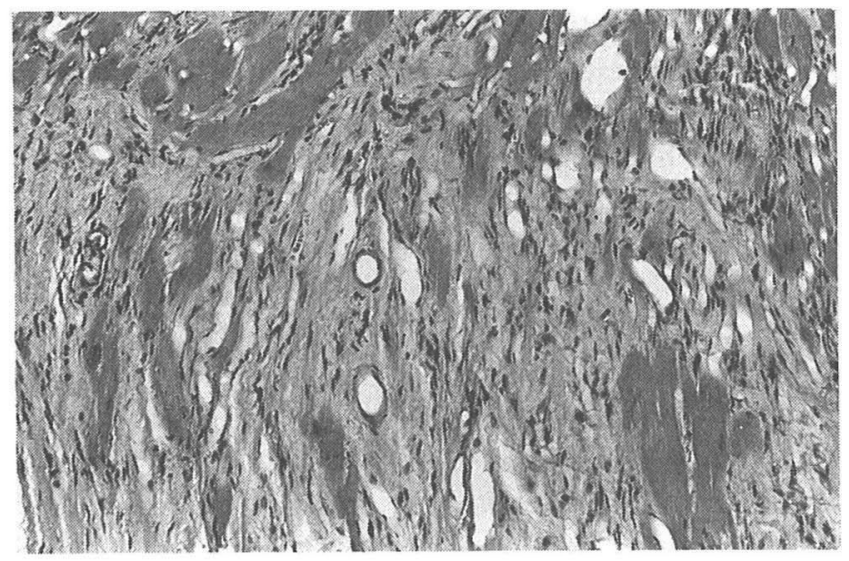

Fig. 4. Fibrosed myocardial infarct of a rat fed with corn-oil-supplemented diet. H \& $\mathrm{E}, \times 107$.

experimental and control rats were almost identical, and were 5.66 \pm 0.30 and $5.65 \pm 0.20$, respectively.

\section{DISCUSSION}

The results of our studies demonstrated that the diet supplemented with menhaden oil by $6 \%$ significantly reduced the arteriosclerosis of the aorta and the incidence of myocardial infarct or focal fibrous replacement of myocardial tissue in SHR. Furthermore, the rats with dietary supplement of menhaden oil exhibited significantly lower plasma cholesterol and triglyceride levels than those without it. It was reported that the development of glomerulosclerosis in some experimental rats was enhanced by high fat diets and improved by such hypolipidemic agents as clofibric acid and Mevinolin (18-20) and also by dietary fish oil $(21,22)$. There is little data reported, however, on the beneficial effects of fish oil on the kidneys and cardiovascular system of the SHR. Dietary menhaden oil reduced the plasma cholesterol and triglyceride levels of SHR. This reduction might have contributed to the significantly lower incidence of aortic sclerosis, myocardial lesions and renal interstitial fibrosis, and to the numerically lower value of the glomerulosclerosis index in rats with menhaden oil than in rats without it. The glomerulosclerosis is akin to arteriosclerotic process (23). It is, therefore, reasonable to speculate that it is under a strong influence of a plasma lipid level (18-20). On the other hand, WHHL rabbits, an animal model of homozygous familial hypercholesterolemia due to defective low density lipoprotein receptors, manifest little evidence of glomerulosclerosis despite severe hypercholesterolemia (24). The species and strain differences in the emergence of glomerulosclerosis seem to epitomize the complexity of the pathogenetic mechanisms of the glomerulosclerosis. Besides plasma lipid levels and composition, fish oil alters cell membrane lipid composition, neutrophil 
activation response, synthesis of eicosanoid, platelet function, and thrombogenicity $(11,25-28)$. The exact mechanisms of biologic action of fish oil in this present experiment, therefore, are extremely complex and far from clear. Since both groups showed almost identical body weight at the time of sacrifice, it was unlikely that the amount of their dietary intake had any significant effects on the results obtained in this experiment.

The results of this present study indicated that menhaden oil that comprised 6 $\mathrm{g} \%$ of the diet had no effect on the systemic blood pressure. Knapp and FitzGerald reported that $15 \mathrm{~g}$ of fish oil administered daily to patients with essential hypertension reduced blood pressure, but $3 \mathrm{~g}$ of daily administration of it had little influence on it (6). Von Au et al. fed SHR a diet containing 10\% fish oil and observed a decrease of the blood pressure (29). The dosage level used by Von Au et al. was significantly higher than that used in our experiment. Data of the present studies, therefore, can be interpreted that the level of dietary supplementation, $6 \mathrm{~g}$ $\%$, might have been insufficient to exert significant influence upon the blood pressure of SHR. This interpretation is in accord with the report by Kingsley and Snyder, who fed SHR a diet containing 5\% fish oil and did not observe a decrease of blood pressure (30).

It was surprising that the numerically lower glomerulosclerosis index of the experimental rats than that of controls was not to a degree of statistical significance. The microscopic cortical fibrosis of the SHR with menhaden oil was, however, significantly less than that of the controls indicating that menhaden oil had beneficial effects to the kidneys of SHR. The glomerulosclerosis in SHR occurs slowly due to a strong preglomerular arteriolar resistance that protects glomerular capillary walls from the hypertensive damage. As a matter of fact, the rats had a normal range of the plasma creatinine level and GFR, and none was in renal failure as late as the 18th month indicating that there was no drastic renal hypertensive damage as late as the 18th month. Longer-term studies than this experiment might be necessary to find any definitive effect of menhaden oil on the glomerulosclerosis of SHR. In summary, the diet containing $6 \mathrm{~g} \%$ of menhaden oil lessened the aortic arteriosclerosis, myocardial damage, renal cortical fibrosis, and plasma cholesterol and triglyceride levels. The data are consistent that the dietary menhaden oil shows a preventive beneficial effect to the glomerulosclerosis of SHR, but are not conclusive of it. Recent realization of an impact of the diet on the incidence of age-associated disease such as arteriosclerosis, myocardial infarct, and some animal models of glomerulosclerosis $(23,31-33)$ calls for clearer understanding of the roles of the diet in the delaying of the onset and the progression of these diseases.

This work was supported by grants from Nat. Kid. Fdtn. and Am. Heart Assoc. The authors are grateful for donation of menhaden oil from Zepata Heynie Corp., Va. Yoko O. Shimamura, B.S., provided technical assistance. Corwyn Miyagishima, a student of Highland Park High Sch., N.J., assisted in the preparation of the illustrations. 


\section{REFERENCES}

1) Band, H. O., Dyerberg, J., and Nielsen, A. B. (1971): Plasma lipid and lipoprotein pattern in Greenlandic west-coast Eskimos. Lancet, 1, 1143-1145.

2) Kagawa, Y., Nishizawa, M., Suzuki, M., Miyatake, T., Hamamoto, T., Goto, K., Motonaga, E., Izumikawa, H., Hirata, H., and Ebihara, A. (1982): Eicosapolyenoic acids of serum lipids of Japanese islanders with low incidence of cardiovascular disease. J. Nutr. Sci. Vitaminol., 28, 441-453.

3) Dyerberg, J., Barg, H. O., Stoffersen, E., Moncada, S., and Vane, J. R. (1978): Eicosapentaenoic acid and prevention of thrombosis and atherosclerosis? Lancet, 2, 117-119.

4) Kromhout, D., Bosschieter, E. B., and Coulander, C. L. (1985): The inverse relation between fish oil consumption and 20-year mortality from coronary heart disease. $N$. Engl. J. Med., 312, 1205-1209.

5) Von Houwelingen, A. C., Kester, A. D. M., and Hornstra, G. (1989): Effect of moderate fish intake on platelet aggregation and ATP release in human blood. Nutr. Res., 9, 1187-1196.

6) Knapp, H. R., and FitzGerald, G. A. (1989): The antihypertensive effects of fish oil. A controlled study of polyunsaturated fatty acid supplements in essential hypertension. N. Engl. J. Med., 320, 1037-1043.

7) Burchard, H. U., and Tischendorf, F. W. (1988): Effect of cod liver oil administration on blood lipid levels, lipoprotein profile and bleeding time. Z. Ernaehrungswiss., 27, 222-228.

8) Dolphin, P. J., Amy, R. M., Koeslag, D. G., Limoges, B. F., and Ressell, J. C. (1988): Reduction of hyperlipidemia in the LA/N-corpulent rat by dietary fish oil containing $n-3$ fatty acids. Biochim. Biophys. Acta, 962, 317-329.

9) Schmidt, E. B., Kristensen, S. D., and Dyerberg, J. (1988): The effect of fish oil on lipids, coagulation and fibrinolysis in patients with angina pectoris. Artery, 15, 316329.

10) Conner, W. E. (1988): Effects of omega-3 fatty acids in hypertriglyceridemic states. Semin. Thromb. Hemostasis, 14, 271-284.

11) Seiss; W., Scherer, B., Boelig, B., Roth, P., Kurzmann, I., and Weber, P. C. (1980): Platelet-membrane fatty acids, platelet aggregation, and thromboxane formation during a mackerel diet. Lancet, 1, 441-444.

12) Lowry, O. H., Rosebrough, N. J., Farr, A. L., and Randall, R. J. (1951): Protein measurement with the Folin phenol reagent. J. Biol. Chem., 193, 265-275.

13) Morrison, A. B., and Howard, R. M. (1966): The functional capacity of hypertrophied nephrons. J. Exp. Med., 123, 829-844.

14) Allain, C. A., Poon, L. S., Chan, C. S. G., Richmond, W., and Fu, P. C. (1974): Enzymatic determination of total serum cholesterol. Clin. Chem., 20, 470-475.

15) Shimamura, T., and Okada, K. (1988): Chelation of intestinal phosphate absorption and experimental glomerulosclerosis. Jpn. J. Exp. Med., 58, 163-167.

16) Shimamura, T., and Morrison, A. B. (1975): A progressive glomerulosclerosis occurring in partial 5/6 nephrectomized rats. Am. J. Pathol., 79, 95-106.

17) McGuire, P. G., Brocks, D. G., Killen, P. D., and Orkin, R. W. (1989): Increased 
deposition of basement membrane macromolecules in specific vessels of the spontaneously hypertensive rat. Am. J. Pathol., 135, 291-299.

18) Kasiske, B. L., O’Donnel, M. P., Chan, M. K., and Keane, W. F. (1988): Treatment of hyperlipidemia reduces glomerular injury in obese Zucker rats. Kidney Int., 333, 667-672.

19) Kasiske, B. L., O’Donnel, M. P., Garvis, W. J., and Kean, W. F. (1988): Pharmacologic treatment of hyperlipidemia reduces glomerular injury in rat $5 / 6$ nephrectomy model of chronic renal failure. Circ. Res., 62, 367-374.

20) Groene, H. J., Walli, A., Groene, E., Niedmann, P., Thiery, J., Seidel, D., and Helmchen, U. (1989): Induction of glomerulosclerosis by dietary lipids. A functional and morphologic study in the rat. Lab. Invest., 60, 433-446.

21) Shimamura, T., and Maesaka, J. J. (1986): Feeding of fish oil containing eicosapentaenoic acid delays the progression of kidney disease induced by renal tissue ablation in obese Zucker rats. Kidney Int., 29, 311.

22) Moorehead, J. F. (1991); Lipids and the pathogenesis of kidney disease. Am. J. Kidney Dis., 17, S65-70.

23) Takahashi, S., and Shimamura, T. (1988): A review of factors modulating experimental glomerulosclerosis. Nihon Univ. J. Med., 30, 101-108.

24) Shimamura, T., Amorosa, L. F., Wilson, A. C., Lelkes, L., and Khachadurian, A. K. (1990): Atherosclerosis and glomerulosclerosis in WHHL rabbits and obese Zucker rats. Jpn. J. Exp. Med., 60, 105-109.

25) Cleland, L. G., Gibson, R. A., Hawkes, J. S., and James, M. J. (1990): Comparison of cell membrane phospholipid fatty acids in five rat strains fed four test diets. Lipids, 25, 559-564.

26) Fletcher, M. P., and Ziboh, V. A. (1990): Effects of dietary supplementation with eicosapentaenoic acid or gamma-linolenic acid on neutrophil phospholipid fatty acid composition and activation responses. Inflammation, 14, 585-597.

27) Brouard, C., and Pascaud, M. (1990): Effects of moderate dietary supplementations with $n-3$ fatty acids on macrophage and lymphocyte phospholipids and macrophage eicosanoid synthesis in the rat. Biochim. Biophys. Acta, 1047, 19-28.

28) Bertomeu, M. C., Crozier, G. L., Haas, T. A., Fleith, M., and Buchanon, M. R. (1990): Selective effects of dietary fats on vascular 13-HODE synthesis and platelet/ vessel wall interactions. Thromb. Res., 59, 819-830.

29) Von Au, D., Brandle, M., Rupp, H., and Jacob, R. (1988): Influence of a diet rich in fish oil on blood pressure, body weight and cardiac hypertrophy in spontaneously hypertensive rats. Eur. J. Appl. Physiol., 58, 97-99.

30) Kingsley, T. R., and Snyder, D. L. (1988): Serum lipids in spontaneously hypertensive rats and Sprague-Dawley rats fed menhaden oil. Lipids, 23, 564-567.

31) Lalich, J. L., Burkholder, P. M., and Paik, W. C. W. (1975): Protein overload nephropathy in rats with unilateral nephrectomy. Arch. Pathol., 99, 72-79.

32) Shimamura, T. (1982): Relationship of dietary intake to the development of glomerulosclerosis in obese Zucker rats. Exp. Mol. Pathol., 36, 423-434.

33) Shimamura, T. (1990): Prevention of 11-deoxycorticosterone-salt-induced glomerular hypertrophy and glomerulosclerosis by dietary phosphate binder. Am. J. Pathol., 136, 549-556. 